\title{
Identification of brefelamide as a novel inhibitor of osteopontin that suppresses invasion of A549 lung cancer cells
}

\author{
JING ZHANG ${ }^{1}$, OSAMU YAMADA ${ }^{1}$, SHINYA KIDA ${ }^{1}$, YOSHIHISA MATSUSHITA ${ }^{1}$, SHINYA MURASE ${ }^{1}$, \\ TOSHIO HATTORI ${ }^{2}$, YUZURU KUBOHARA ${ }^{3}$, HARUHISA KIKUCHI ${ }^{4}$ and YOSHITERU OSHIMA ${ }^{4}$ \\ ${ }^{1}$ Research and Development Center, FUSO Pharmaceutical Industries, Ltd., Osaka 536-8523; \\ ${ }^{2}$ Department of Disaster-related Infectious Disease, International Research Institute of Disaster Science, \\ Tohoku University, Sendai, Miyagi 980-8575; ${ }^{3}$ Graduate School of Health and Sports Science, \\ Juntendo University, Inzai, Chiba 270-1695; ${ }^{4}$ Laboratory of Natural Product Chemistry, \\ Graduate School of Pharmaceutical Sciences, Tohoku University, Sendai, Miyagi 980-8578, Japan
}

Received March 23, 2016; Accepted August 1, 2016

DOI: 10.3892/or.2016.5006

\begin{abstract}
The contribution of aberrant osteopontin (OPN) expression to tumor progression and metastasis has been documented in a wide spectrum of malignancies, and targeted inhibition of OPN has therefore emerged as an attractive strategy for cancer therapy. Transcription of OPN is regulated by various transcription factors, and our recently published study demonstrated that downregulation of OPN is an important event in the TGF- $\beta$ cytostatic program. We report here that brefelamide exerts an inhibitory effect on OPN expression and function in A549 human lung carcinoma cells. The promoter, RNA, and protein levels of OPN were decreased in brefelamide-treated A549 cells, which was accompanied by reduced invasive ability in vitro. OPN inhibition by brefelamide was largely abrogated by disruption of a putative TGF- $\beta$ inhibitory element in the OPN promoter. Treatment with brefelamide induced Smad4 expression, and knockdown of Smad4 by RNA interference partially diminished the inhibitory effect of brefelamide on OPN. These results indicate that brefelamide inhibited OPN-mediated cell invasion through restoration of the OPN repression by TGF- $\beta /$ Smad signaling. Together with the reported antiproliferative property, our findings suggest that brefelamide might serve as a potential candidate for the development of a new antitumor and antimetastatic agent.
\end{abstract}

\section{Introduction}

Metastasis is implicated in cancer aggressiveness and poor clinical outcome, which accounts for $\sim 90 \%$ of all cancer-related

Correspondence to: Dr Jing Zhang or Dr Osamu Yamada, Research and Development Center, FUSO Pharmaceutical Industries, Ltd., 2-3-30 Morinomiya, Joto-ku, Osaka 536-8523, Japan

E-mail: j-zhang@fuso-pharm.co.jp

E-mail: o-yamada@fuso-pharm.co.jp

Key words: brefelamide, osteopontin, TGF- $\beta$, Smad4, lung cancer deaths $(1,2)$. Metastatic cascade is a multistep process composed of a series of events such as invasion, intravasation, transport, extravasation, and colonization (3). Tumor metastatic progression is driven not only by genetic aberrations intrinsic to malignant cells but by pro-metastatic factors from the surrounding environment (4). Besides being enriched with genetically altered cancer cells, the tumor microenvironment (TME) consists of heterogeneous mixture of non-cancerous cells, including fibroblasts, immune cells, and endothelial cells in conjunction with extracellular matrix (ECM) called stroma $(5,6)$. The progression of cancer towards metastasis is regulated by a time-evolving network of interactions between neoplastic cells and the associated stroma. In addition to providing a physical support for architecture, ECM represents an important player in mediating communication between cells and signaling cascades involved in cell migration, proliferation, survival and differentiation (7-9). Matricellular proteins, a family of non-structural ECM proteins, play important roles in modulating cell-cell and cell-matrix interactions (10). Multiple members of the matricellular protein family have been identified as important regulators in conferring various aspects of cancer cell behavior, such as epithelial-mesenchymal transition, angiogenesis, cell migration, survival, proliferation, and ECM degradation (11).

Osteopontin (OPN) is a multifunctional matricellular protein produced by a broad range of cells including osteoclasts, macrophages, T cells, kidneys, and vascular smooth muscle cells (12). OPN modulates multiple cellular processes, such as inflammation, wound healing, bone formation and remodeling, as well as tumor growth and metastasis $(13,14)$. By interaction with $\alpha v \beta 3$ integrins and CD44, OPN signals a complex cascade promoting proliferation, migration and invasion of tumor cells, inhibiting apoptosis, and facilitating extracellular remodeling and angiogenic processes (15-18). In line with these experimental observations, the pro-tumorigenic and pro-metastatic activities of OPN were suggested in numerous clinical laboratory analyses. It has been shown, for example, that OPN plasma concentration correlates well with tumor grade and progression in multiple cancers such as breast and ovarian cancer (19). Therefore, targeted inhibition of OPN represents a rational and promising therapeutic strategy in oncology. 
Brefelamide is an aromatic amide isolated from Dictyostelium cellular slim molds. It was previously shown that brefelamide inhibits the proliferation of human-derived $1321 \mathrm{~N} 1$ astrocytoma cells (20), and the antiproliferative effect was associated with a reduced phosphorylation of epidermal grow th factor receptor (EGFR) and attenuated EGFR-mediated ERK signaling cascade (21). In this study, we further explored the feasibility of brefelamide as an anticancer therapeutic agent and found that brefelamide inhibited OPN gene expression and consequently reduced the invasion of human lung adenocarcinoma-derived A549 cells. The inhibition of OPN by brefelamide appears to involve induction of Smad4 expression and subsequent restoration of the TGF- $\beta / \mathrm{Smad}$-mediated OPN repression.

\section{Materials and methods}

Plasmids. The reporter vector pOPN1-luc, as well as its mutants pOPN-lucmTIE1 an 2 have been described previously $(22,23)$ The plasmid expressing shRNA against Smad4 under the control of the U6 promoter was constructed as previously described $(23,24)$. For construction of pcDNA3.1-OPN, full-length cDNA fragment of OPN open reading frame was amplified with primers 5'-ataaagcttATGAGAATTGCAGTG ATTTG-3' and 5'-atatctagaTTAATTGACCTCAGAAG ATG-3', digested with HindIII and XbaI, and ligated into pcDNA3.1 vector (Invitrogen). The sequence in the construct was confirmed by nucleotide sequencing.

Cells. All cell lines were purchased from American Type Culture Collection (ATCC) and maintained in Dulbecco's modified Eagle's medium (DMEM, invitrogen) supplemented with $10 \%$ fetal bovine serum (FBS) and $50 \mathrm{U} / \mathrm{ml}$ penicillin and streptomycin in a $5 \% \mathrm{CO}_{2}$ humidified atmosphere. The cell line, A549/OPN-luc, was established by co-transfection of A549 cells with pOPN1-luc and pPUR (Clontech Laboratories, Inc.), followed by selection in the presence of $1 \mu \mathrm{g} / \mathrm{ml}$ puromycin (Sigma).

Chemicals. Brefelamide was synthesized as described previously (20). It was dissolved in DMSO at a concentration of $50 \mathrm{mmol} / \mathrm{l}$ and stored at $-20^{\circ} \mathrm{C}$. Aliquots of this stock solution were subsequently diluted to the indicated concentrations before the treatment of the cells. Cisplatin was purchased from Wako Pure Chemical Industries, Ltd. (Osaka, Japan) and sorafenib was purchased from Cayman Chemicals (Ann Arbor, MI, USA).

ELISA. For OPN detection, supernatants were collected from culture after a 48 -h treatment in the absence or presence of brefelamide, and OPN levels in the culture medium were determined with OPN ELISA kit (R\&D systems).

Real-time RT-PCR. Cells were lysed with TRIzol reagent (Invitrogen), and total RNA was extracted according to the manufacturer's instructions. After treatment with RNase-Free DNase (Promega), the DNA-Free RNA (250 ng) was used for the synthesis of the first-strand cDNA at $42^{\circ} \mathrm{C}$ for 60 min using M-MLV Reverse Transcriptase (Invitrogen). Real-time quantitative PCR using Power SYBR Green PCR Master Mix was conducted for 40 cycles at $95^{\circ} \mathrm{C}$ for $15 \mathrm{sec}$ and at $60^{\circ} \mathrm{C}$ for $1 \mathrm{~min}$ in a 96-well format on StepOnePlus ${ }^{\mathrm{TM}}$ Real-Time PCR System (both from Applied Biosystems). Primer sequences were as follows: OPN forward, 5'-ACTCGTCTCAGGCCAG TTG-3' and reverse, 5'-CGTTGGACTTGGAAGG-3'; Smad4 forward, 5'-GCATCGACAGAGACATACAG-3' and reverse, 5'-AATCCATTCTGCTGCTGTCC-3'; GAPDH forward, 5'-TGATGACATCAAGAAGGTGG-3' and reverse, 5'-TCC TTGGAGGCCATGTGGGC-3'.

Transient transfection and luciferase assay. Cells were seeded at $1 \times 10^{5}$ in $1 \mathrm{ml} \mathrm{medium} /$ well of 12 -well plates $24 \mathrm{~h}$ before transfection. Indicated plasmid DNAs were transfected into cells with Effectene Transfection Reagent (Qiagen). For each transient transfection, pRL-TK vector (Promega) was co-transfected as an internal control to normalize the transfection efficiency. The cells were harvested at a 48 -h post-transfection, and the cell lysates were prepared for luciferase assay with Dual-Luciferase Reporter Assay System (Promega) according to the manufacturer's instructions. Luciferase activities were measured using a GloMax ${ }^{\circledR}$ 20/20 Luminometer (Promega).

Invasion assays. A549 cells were suspended in DMEM containing $0.1 \%$ bovine serum albumin and seeded into cell culture inserts constructed with an $8-\mu \mathrm{m}$ porous membrane, which was pre-coated with Matrigel $(10 \mathrm{mg} / \mathrm{ml}$; BD Biosciences). As a chemoattractant, DMEM supplemented with $10 \%$ FCS was added outside the inserts and incubated for $48 \mathrm{~h}$ at $37^{\circ} \mathrm{C}$. The cells were labeled with Calcein AM solution (BD Biosciences). The number of cells which had migrated through the membrane was quantified using SpectraMax M5 microplate reader (Molecular Devices). Three sets of experiments were carried out, each one in triplicate.

Cell proliferation assay. Each cell line was plated in 96-well plates at a concentration of $1 \times 10^{4}$ cells/well in a volume of $100 \mu 1$. Twenty-four hours later, brefelamide or another anticancer reagent was added, individually or in combination, to the cells at various concentrations. After an additional 72-h culture, cell growth was measured with Cell Proliferation Reagent WST-1 (Roche Diagnostics) according to the manufacturer's instructions. The half maximal inhibitory concentration $\left(\mathrm{IC}_{50}\right)$ of compounds was determined from the dose-response curves.

Statistics. All p-values were determined using Dunnett's test or Tukey-Kramer test. The differences were considered significant at $\mathrm{p}<0.05$.

\section{Results}

Inhibition of OPN expression by brefelamide. In an attempt to screen compounds that have the potential to inhibit the transcription of OPN, we developed an experimental system employing A549 human lung adenocarcinoma epithelial cell line stably transfected with pOPN1-luc, in which luciferase gene is directed under the control of human OPN promoter (22). We monitored the luciferase expression in A549/OPN-luc after treatment for $48 \mathrm{~h}$ with increasing concentration of brefelamide. As shown in Fig. 1A, luciferase expression in A549/OPN-luc cells was dose-dependently suppressed by the brefelamide treatment. 
A

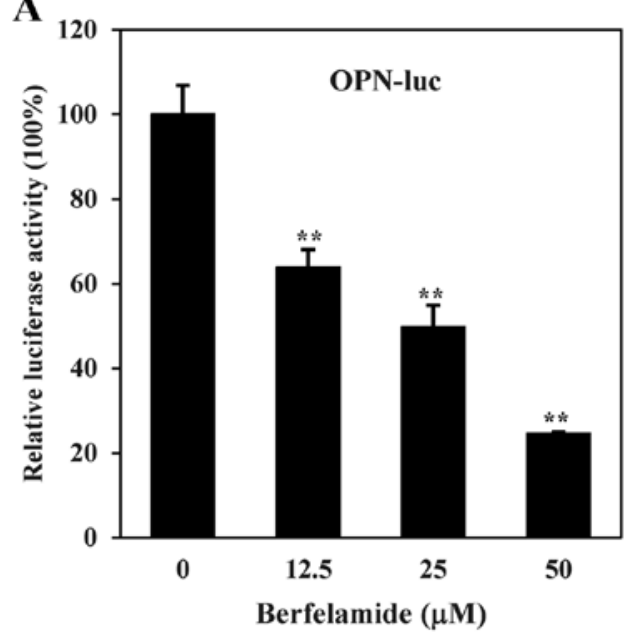

B

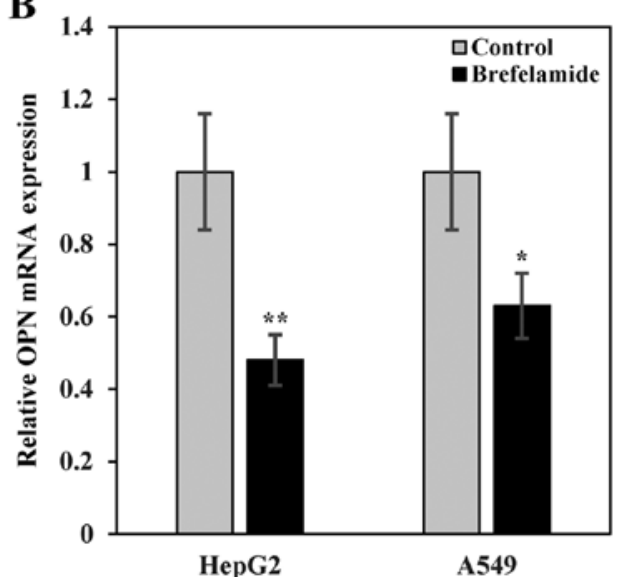

C

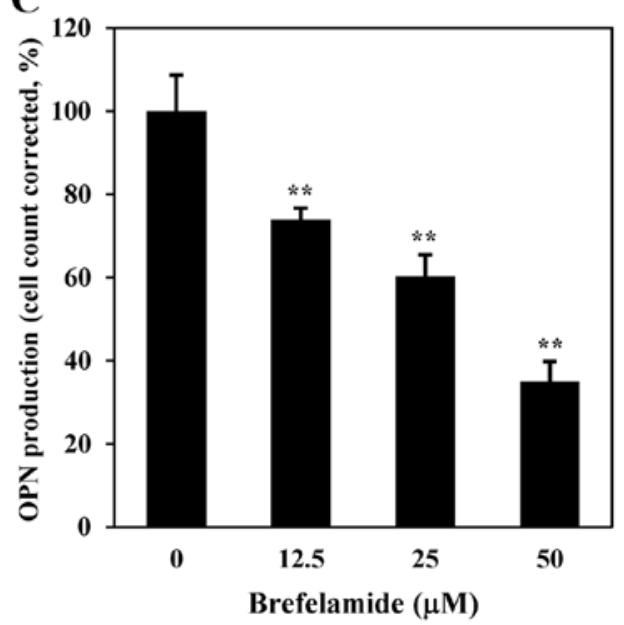

Figure 1. Suppression of OPN by brefelamide. (A) A549 cells stably transfected with pOPN1-luc, were cultured in the absence or presence of various concentrations of brefelamide. Luciferase activities in the lysates were measured at a 48-h post-transfection. (B) HepG2 or A549 cells were either untreated or incubated with brefelamide $(25 \mu \mathrm{M})$ for $24 \mathrm{~h}$, then RNA was prepared and subjected to reverse transcription and quantitative real-time PCR. All samples were normalized with the expression level of GAPDH. Each condition was done in triplicate. (C) A549 cells were cultured in the absence or presence of various concentrations of brefelamide. After $48 \mathrm{~h}$ of culture, aliquots of supernatant were analyzed for quantitation of OPN production by ELISA, and cell counts were simultaneously measured with Cell Proliferation Reagent WST-1 for normalization. Normalized OPN secretion from vehicle-treated control was set as $100 \%$, and those from other brefelamide-treated groups are expressed as relative percentage. Results are presented as the means \pm standard deviations of three independent triplicate transfections. ${ }^{*} \mathrm{P}<0.05,{ }^{* *} \mathrm{p}<0.01$ vs. vehicle control group. OPN, osteopontin.
Similar results were obtained in real-time RT-PCR, which showed a reduction of OPN mRNA in brefelamide-treated HepG2 and A549 cells (Fig. 1B), confirming a transcriptional repression of OPN by brefelamide. When OPN production in the culture supernatant was measured by ELISA, we observed a concentration-dependent reduction in OPN production in A549 cells exposed to brefelamide $(183 \pm 7,115 \pm 6$ and $57 \pm 2 \mathrm{ng} / \mathrm{ml}$ at a concentration of $12.5,25$ and $50 \mu \mathrm{M}$, respectively), when compared to that from DMSO (mock)-treated A549 cells (283 $\pm 7 \mathrm{ng} / \mathrm{ml})$ (Fig. 1C).

Effect of brefelamide on cell invasion. OPN is an extracellular matrix protein involved in cell motility. We next performed Matrigel invasion assay to investigate the functional impact of OPN suppression by brefelamide on A549 cells. As shown in Fig. 2A, the cell numbers invaded through the Matrigel after an exposure of brefelamide at the concentration of 12.5 and $25 \mu \mathrm{M}$ were significantly lower than that of untreated control (1120 \pm 285 and $719 \pm 176$ vs. $2694 \pm 421, \mathrm{p}<0.01)$, indicating that brefelamide decreases the invasion activity of cells. Further, anti-invasive activity of brefelamide was weakened in cells incubated with the conditioned medium from pcDNA3.1-OPN transfectant, which contained $327 \mathrm{ng} / \mathrm{ml}$ of OPN as detected by ELISA (Fig. 2B). This finding indicates that brefelamide inhibits cell invasion at least partially by its suppression of OPN production. An inhibitory effect of brefelamide on cell migration was also observed in wound healing assay (data not shown). These data suggest that suppression of OPN expression by brefelamide can inhibit the migratory and invasive activity of the cancer cells, implying the potential of brefelamide as an antimetastatic therapeutic agent.

Sensitization of cancer cells to conventional anticancer drugs. Brefelamide has been reported to suppress the proliferation of astrocytoma cells by inhibiting ERK phosphorylation (21). We next performed growth inhibition assay to investigate whether brefelamide can enhance the chemosensitivity of cancer cells to conventional anticancer agents such as cisplatin, etoposide and sorafenib. The $\mathrm{IC}_{50}$ of cisplatin alone was 107.0 and $183.9 \mu \mathrm{M}$ in A549 and HepG2 cells, respectively, which was decreased to 48.8 and $53.0 \mu \mathrm{M}$ when co-treated with brefelamide (Table I). Reduction in the $\mathrm{IC}_{50}$ value by combination with brefelamide was also observed in the case of etoposide ( $\mathrm{IC}_{50}$ from 55.1 to $25.4 \mu \mathrm{M}$ in $\mathrm{A} 549$ cells) and sorafenib ( $\mathrm{IC}_{50}$ from 2.3 to $0.5 \mu \mathrm{M}$ in HepG2 cells). This indicates that brefelamide treatment sensitized cancer cells to these anticancer drugs, suggesting that brefelamide may provide a potential strategy to overcome chemoresistance.

Induction of Smad4 by brefelamide. To gain some insights into the molecular mechanism underlying the brefelamide-mediated OPN inhibition, we conducted microarray analysis to clarify the different gene expression profiles between brefelamide- and mock-treated A549 cells. We found 1,382 genes with expression altered $\geq 1.5$-fold after exposure to brefelamide, which were distributed into distinct functional groups including those involved in proliferation and cell motility. One of these genes, Smad4, whose expression was induced after brefelamide treatment, was chosen for further study. We focused on Smad4 in view of the previous publication 
A

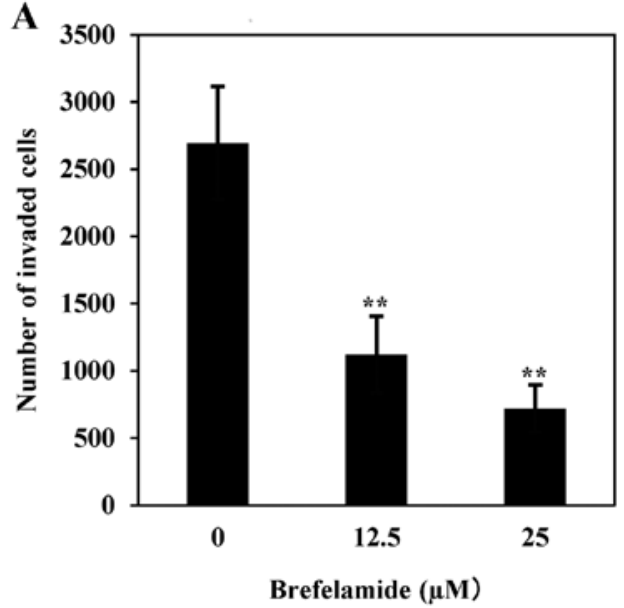

B

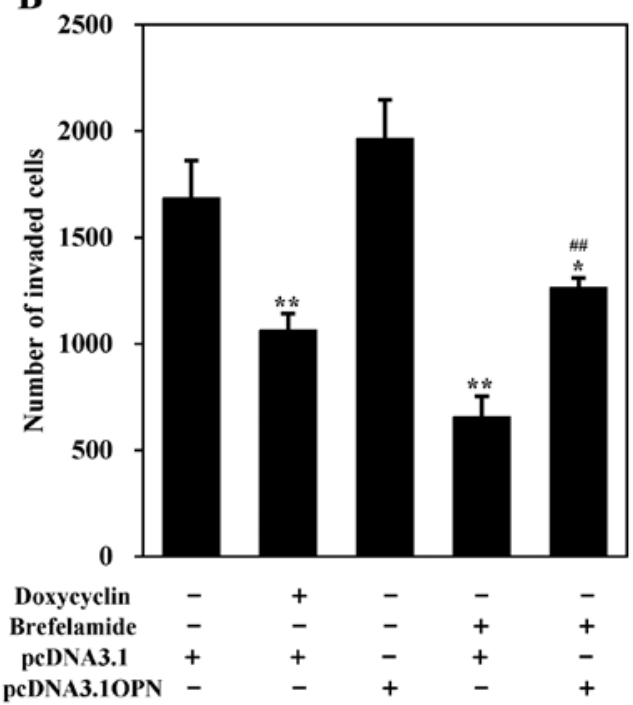

Figure 2. Suppression of cell invasion by brefelamide. (A) Matrigel invasion assay on A549 cells after treatment with the indicated concentrations of brefelamide. The cells which had migrated through Matrigel pre-coated membrane were labeled with Calcein AM, and quantified using SpectraMax M5 microplate reader as described in 'Materials and methods'. ${ }^{* *} \mathrm{P}<0.01$ vs. vehicle control. (B) Partial attenuation of anti-invasive activity of brefelamide after incubation with conditioned medium derived from pcDNA3.1-OPN transfectant. A549 cells were exposed to conditioned medium $(50 \%, \mathrm{v} / \mathrm{v})$ from cells transfected with pcDNA3.1 control vector or pcDNA3.1-OPN. Doxycyclin, a matrix metalloproteinase inhibitor, was included as a control. Invaded cells were determined and calculated as described in (A). Each bar represents the mean \pm standard deviation. ${ }^{*} \mathrm{P}<0.05,{ }^{* *} \mathrm{p}<0.01$ vs. group treated with vehicle and condition medium from pcDNA3.1 transfectant; ${ }^{\# \#} \mathrm{p}<0.01$ vs. group treated with brefelamide and condition medium from pcDNA3.1 transfectant. OPN, osteopontin.

demonstrating deletion of Smad4 in metastatic-prone condition in the prostate cancer model was associated with aberrant expression of OPN (25), and further, our recent study demonstrating that OPN was a downstream target negatively regulated by TGF- $\beta /$ Smad signaling (23). These observations prompted us to hypothesize that brefelamide suppresses OPN expression via induction of Smad4. To investigate this possibility, expression of Smad4 mRNA was determined by real-time RT-PCR in cells cultured in the absence or presence of brefelamide. Consistent with that obtained from the microarray analysis, endogenous Smad4 mRNA in HepG2 or A549 cells was enhanced by brefelamide treatment (Fig. 3A).
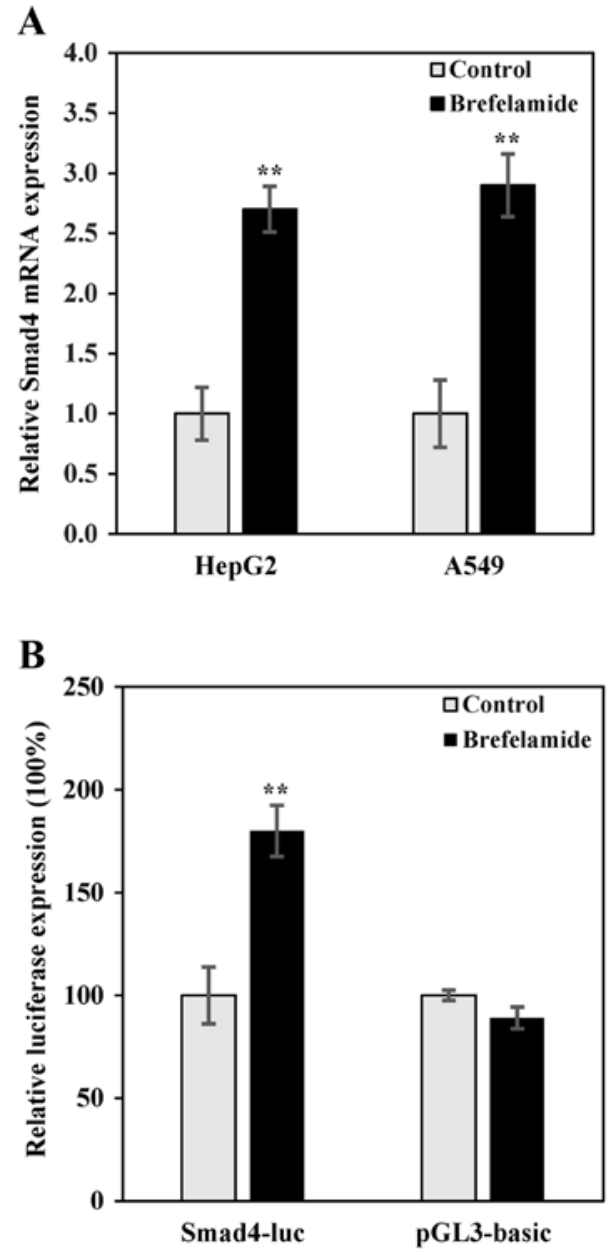

Figure 3. Induction of Smad4 by brefelamide. (A) HepG2 or A549 cells were either untreated or incubated with brefelamide $(25 \mu \mathrm{M})$ for $24 \mathrm{~h}$, then RNA was prepared and subjected to reverse transcription and quantitative real-time PCR. All samples were normalized with the expression level of GAPDH as described in Fig. 1. Each condition was done in triplicate. (B) A549 cells were transfected with pSmad4-luc or empty control (pGL3-basic), cultured in the absence or presence of brefelamide $(25 \mu \mathrm{M})$ for $48 \mathrm{~h}$, cells were harvested and relative luciferase activities were determined. Renilla luciferase activities from co-transfected pRL-TK were used to normalize the transfection efficiency. Normalized luciferase activity from mock-treated transfectant was set as $100 \%$, and those in others are expressed as relative percentage. Representative results are from three independent experiments. ${ }^{* * *} \mathrm{P}<0.01$ vs. vehicle control group.

Table I. Reduction in the $\mathrm{IC}_{50}$ value $(\mu \mathrm{M})$ of anticancer drugs used in combination with brefelamide.

\begin{tabular}{|c|c|c|c|c|}
\hline \multirow[b]{2}{*}{ Cells } & \multicolumn{2}{|c|}{ Cisplatin } & \multicolumn{2}{|c|}{ Etoposide } \\
\hline & Isolation & Combination & Isolation & Combination $^{\mathrm{a}}$ \\
\hline \multirow[t]{2}{*}{ A549 } & $>100$ & 48.8 & 55.1 & 25.4 \\
\hline & \multicolumn{2}{|c|}{ Cisplatin } & \multicolumn{2}{|c|}{ Sorafenib } \\
\hline Cells & Isolation & Combination ${ }^{\mathrm{b}}$ & Isolation & Combination \\
\hline HepG2 & $>100$ & 53 & 2.3 & 0.5 \\
\hline
\end{tabular}

${ }^{\mathrm{a} C o m b i n a t i o n}$ with $25 \mu \mathrm{M}$ of brefelamide; ${ }^{\mathrm{b}}$ Combination with $12.5 \mu \mathrm{M}$ of brefelamide. $\mathrm{IC}_{50}$, half maximal inhibitory concentration. 
$\mathbf{A}$
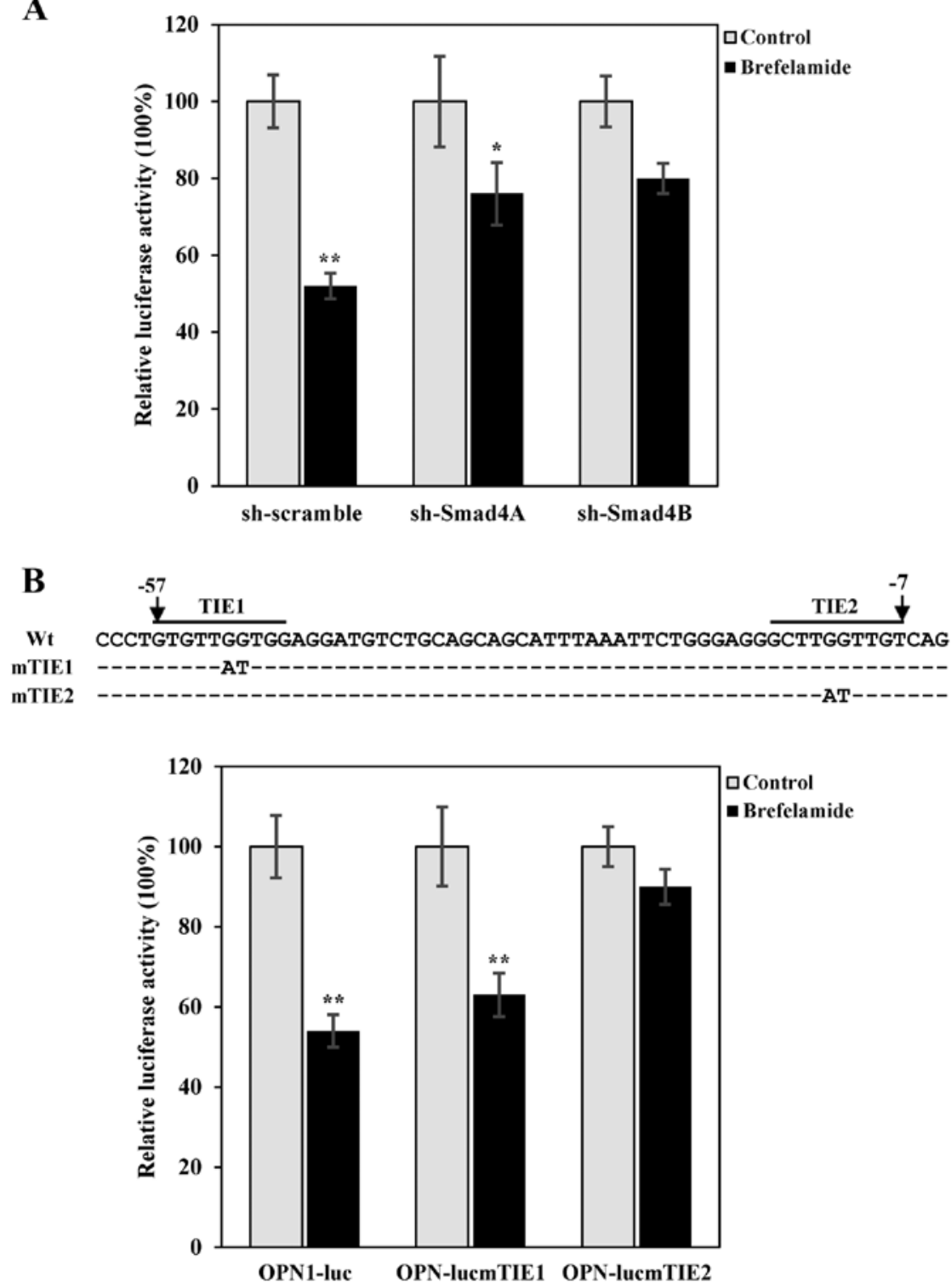

Figure 4. Involvement of Smad4 in brefelamide-mediated OPN inhibition. (A) Knockdown of Smad4 expression partially attenuated OPN inhibition by brefelamide. A549 cells were transfected with pOPN1-luc and shRNA expressing vector. After a culture in the absence or presence of brefelamide ( $25 \mu \mathrm{M})$ for $48 \mathrm{~h}$, cells were harvested and relative luciferase activities were determined and calculated as described in Fig. 3. (B) Delineation of OPN promoter sequence around the putative TIE elements (upper panel). A549 cells were transiently transfected with reporter vectors under the control of OPN promoter or its mutants pOPN-lucmTIE1 and 2, in which the putative TIE site 1 or 2 was mutated as delineated, followed by a culture in the absence or presence of $25 \mu \mathrm{M}$ of brefelamide for $48 \mathrm{~h}$. Relative luciferase activities were determined and calculated as described in Fig. 3 (lower panel). The results are from three independent triplicate transfections. ${ }^{*} \mathrm{P}<0.05,{ }^{* *} \mathrm{p}<0.01$ vs. vehicle control group. OPN, osteopontin.

Similar results were also obtained in the reporter assay with pSmad4-luc, in which luciferase gene is directed under the control of human Smad4 promoter. As shown in Fig. 3B, Smad4-directed luciferase expression was increased in A549 cells treated with brefelamide, while no effect was observed on empty vector (pGL3-basic), confirming a transcriptional induction of Smad4 by brefelamide.

Involvement of TGF- $\beta /$ Smad4 signaling in brefelamide-mediated OPN suppression. To confirm a mechanistic role for Smad4 in brefelamide-mediated OPN suppression, we next took a different approach using shRNA-mediated silencing of the expression of Smad4. pOPN1-luc was transfected with construct expressing control-(sh-scramble) or two independent sh-Smad4
(sh-Smad4A and B), which resulted in a moderate knockdown of Smad4 as confirmed by quantitative real-time PCR (23). Consistent with the aforementioned results, OPN promoter activity in cells transfected with sh-scramble was decreased in cells treated with brefelamide, and notably, the extent of brefelamide-mediated OPN suppression was partially attenuated in cells transfected with either sh-Smad4A or B (Fig. 4A), suggesting that Smad4 is a mediator involved in the inhibition of OPN by brefelamide. Furthermore, brefelamide-induced OPN repression was largely abrogated in reporter assay with pOPN-lucmTIE2 in which the putative TGF- $\beta$ inhibitory element was disrupted (23), whereas disruption of TIE1 did not significantly alter OPN inhibition by brefelamide (Fig. 4B). These data provide an additional line of evidence supporting 
that brefelamide inhibits OPN through inducing Smad4 and subsequently restoring the negative regulation of OPN by TGF- $\beta /$ Smad signaling.

\section{Discussion}

Implication of OPN in the development and progression of multiple tumor types suggests that targeted inhibition of OPN may represent a promising therapeutic modality against malignant diseases. A variety of strategies have been endeavored to ablate OPN function, examples of such approaches include silencing of OPN using RNAi technology, blocking OPN activity using specific antibodies, RNA aptamer, and small-molecule inhibitors (26-29). Transcriptional regulation of OPN is complex and involves various transcription factors, including AP-1, Ets, Myc, and v-Src $(30,31)$. More recently, we demonstrated that OPN is a downstream target negatively regulated by TGF- $\beta$ signaling, and deregulation of OPN by TGF- $\beta$ is linked with loss of TGF- $\beta$ cytostatic responsiveness (23).

Here, we identify brefelamide as a novel OPN inhibitor, and the molecular basis for OPN inhibition by brefelamide appears to be associated with induction of Smad4 and consequent restoration of OPN repression by TGF- $\beta / \mathrm{Smad}$ signaling. Our conclusion was inferred based on the following observations: i) brefelamide suppresses OPN expression, with subsequent inhibition of cell invasion; ii) brefelamide induces Smad4 expression; iii) elimination of a TIE-like element largely abolishes OPN suppression by brefelamide; and iv) shRNA-mediated knockdown of Smad4 partially abrogates OPN inhibition by brefelamide. Together, these findings suggest that brefelamide inhibits OPN expression and OPN-mediated invasion through restoration of Smad4-mediated TGF- $\beta / \mathrm{OPN}$ regulatory axis.

A couple of reports linked aberrant OPN expression to the activated ERK pathway, demonstrating that OPN is a downstream target of ERK/AP-1 signaling pathway (32). Further, brefelamide was reported to inhibit EGF-dependent activation of the ERK pathway (20). Thus, the OPN inhibition observed here may occur as a consequence of brefelamide-mediated suppression of the EGFR-dependent ERK activation. The microarray-based comparison analysis, however, did not show significant change in the expression level of ERK signaling-associated genes in brefelamide-treated A549 cells (data not shown), and further, brefelamide-mediated OPN inhibition was largely diminished in pOPN-lucmTIE2, in which the identified AP-1-binding motifs were intact. Thus, it was largely excluded, if not completely, that the OPN suppression by brefelamide was attributable to its inhibitory effect on ERK signaling pathway. Given the importance of cellular context in conferring the sensitivity to ERK inhibition (33), it may not be surprising that EGFR-ERK pathway was inhibited in brefelamide-treated astrocytoma $1321 \mathrm{~N} 1$ cells, but not in lung adenocarcinoma A549 cells.

Consistent with the results from precedent microarray analysis, real-time quantitative PCR and reporter assay showed increased expression of Smad4 after treatment with brefelamide. Previous studies have shown that EGF triggers GSK3 phosphorylation of Smad4 through activation of the ERK pathway, subsequently resulting in the polyubiquitination and proteasomal degradation of Smad4 (34). Considering the property of brefelamide in inhibiting ERK signaling pathway, it is suggested that, in addition to increasing Smad4 synthesis, brefelamide may enhance the stability of Smad4 protein by inhibiting EGF/ERK-mediated Smad4 ubiquitination. The ability of brefelamide to induce Smad4 activity is of potential clinical relevance. Smad4 is a major tumor suppressor that is frequently deleted or inactive in cancers of the pancreas, gastrointestine, and skin (35-37). Decreased Smad4 expression has been reported in various human cancers and the Smad4 expression level is inversely correlated with tumor grade and TNM stage. Actually, it was reported that re-establishment of Smad4 suppressed Wnt/ $\beta$-catenin signaling activity and increased the expression of E-cadherin in human colon carcinoma cells, both of which were suggested to be involved in the migration-suppressive function of Smad4 (38). Also, adenoviral-mediated restoration of Smad4 inhibited tumor growth, invasion and angiogenesis in pancreatic adenocarcinoma cells. Negative regulation of downstream targets including VEGF, MMP-2, MMP-9, and especially ETS-1, by ectopically expressed Smad4 was demonstrated as the mechanism underlying the observed antitumor effects (39). It is thus probable, although remains to be proven, that besides OPN, these downstream targets of Smad4 may also be suppressed by brefelamide-mediated Smad4 induction. Studies are underway to investigate this hypothesis. If confirmed, breferlamide may be a promising therapeutic candidate that targets the malignancies associated with loss of Smad4 expression.

When used in combination with the conventional anticancer drugs, brefelamide re-sensitized A549 and HepG2 cells to cisplatin, and decreased the $\mathrm{IC}_{50}$ value of etoposide and sorafenib in A549 and HepG2 cells, respectively. In addition to a crucial role in cancer progression, invasion and metastasis, overexpressed OPN has been reported to be involved in the development of resistance to chemotherapy by inhibiting apoptosis (40). Thus, brefelamide-mediated sensitizing effect may occur as a consequence of OPN inhibition. Indeed, silencing of OPN by siRNA significantly enhanced chemotherapy sensitivity of breast cancer cells (41). Additionally, microarray analysis revealed that p53 tumor suppressor and its downstream target genes such as p21 were induced in brefelamide-treated A549 cells, and further, our preliminary data indicated that $\mathrm{p} 53$-driven luciferase reporter was activated by treatment with brefelamide. Both of which suggested that brefelamide may activate p53-regulated pro-apoptotic signaling pathways, consequently potentiating drug-mediated apoptosis.

Different from gene silencing strategies, small molecules are usually not specific for a single molecular target. Simultaneously affecting a set of functionally linked genes sometimes leads to enhanced efficacy. The conventional agents such as cisplatin and doxorubicin, for example, have been identified to affect the expression of multiple genes involved in cell proliferation and apoptosis. It may also be the case that brefelamide may affect other molecules besides OPN. Consistent with this hypothesis, it was found that incubation with the OPN-containing conditioned medium did not fully abolish the anti-invasive activity of brefelamide (Fig. 2B), the partially retained inhibition may 
be attributable to the brefelamide's action on other genes regulating cell motility and invasion. Actually, microarray analysis of brefelamide-treated A549 cells revealed altered expression of genes associated with cell migration and invasion. Nonetheless, the data presented here suggest that brefelamide inhibits invasion of A549 cells at least partially through downregulation of OPN. On the contrary, interaction of drugs with molecules other than the intended target may cause an undesired side-effect. Unintended side-effect is also an issue of concern in the case of brefelamide. As judged by morphologic observation and viability measurement, however, no discernible adverse effects were observed in brefelamide-treated A549 and HepG 2 cells. Further independent experiments are required to delineate off-target-based toxicological effects of brefelamide.

In conclusion, the results presented here indicated that brefelamide suppressed OPN expression and OPN-mediated cell invasion. This is likely mediated through inducing Smad4 expression and consequently restoring Smad4-mediated TGF- $\beta$ /OPN regulatory axis. These data suggest the potential utility of brefelamide as antimetastatic agent in patients with OPN-overexpressed malignancies.

\section{References}

1. Weigelt B, Peterse JL and van 't Veer LJ: Breast cancer metastasis: Markers and models. Nat Rev Cancer 5: 591-602, 2005.

2. Hanahan D and Weinberg RA: Hallmarks of cancer: The next generation. Cell 144: 646-674, 2011

3. Nguyen DX, Bos PD and Massagué J: Metastasis: From dissemination to organ-specific colonization. Nat Rev Cancer 9: 274-284, 2009.

4. Joyce JA and Pollard JW: Microenvironmental regulation of metastasis. Nat Rev Cancer 9: 239-252, 2009.

5. Otranto M, Sarrazy V, Bonté F, Hinz B, Gabbiani G and Desmoulière A: The role of the myofibroblast in tumor stroma remodeling. Cell Adhes Migr 6: 203-219, 2012.

6. Mao Y, Keller ET, Garfield DH, Shen K and Wang J: Stromal cells in tumor microenvironment and breast cancer. Cancer Metastasis Rev 32: 303-315, 2013.

7. Geiger B, Bershadsky A, Pankov R and Yamada KM: Transmembrane crosstalk between the extracellular matrix - cytoskeleton crosstalk. Nat Rev Mol Cell Biol 2: 793-805, 2001.

8. Discher DE, Janmey P and Wang YL: Tissue cells feel and respond to the stiffness of their substrate. Science 310: 1139-1143, 2005.

9. Engler AJ, Sen S, Sweeney HL and Discher DE: Matrix elasticity directs stem cell lineage specification. Cell 126: 677-689, 2006.

10. Roberts DD: Emerging functions of matricellular proteins. Cell Mol Life Sci 68: 3133-3136, 2011.

11. Chiodoni C, Colombo MP and Sangaletti S: Matricellular proteins: From homeostasis to inflammation, cancer, and metastasis. Cancer Metastasis Rev 29: 295-307, 2010

12. Brown LF, Berse B, Van de Water L, Papadopoulos-Sergiou A, Perruzzi CA, Manseau EJ, Dvorak HF and Senger DR: Expression and distribution of osteopontin in human tissues: Widespread association with luminal epithelial surfaces. Mol Biol Cell 3: 1169-1180, 1992.

13. Rangaswami H, Bulbule A and Kundu GC: Osteopontin: Role in cell signaling and cancer progression. Trends Cell Biol 16: 79-87, 2006.

14. Anborgh PH, Mutrie JC, Tuck AB and Chambers AF: Role of the metastasis-promoting protein osteopontin in the tumour microenvironment. J Cell Mol Med 14: 2037-2044, 2010.

15. Tuck AB, Arsenault DM, O'Malley FP, Hota C, Ling MC, Wilson SM and Chambers AF: Osteopontin induces increased invasiveness and plasminogen activator expression of human mammary epithelial cells. Oncogene 18: 4237-4246, 1999.

16. Lin YH and Yang-Yen HF: The osteopontin-CD44 survival signal involves activation of the phosphatidylinositol 3-kinase/Akt signaling pathway. J Biol Chem 276: 46024-46030, 2001.
17. Philip S, Bulbule A and Kundu GC: Osteopontin stimulates tumor growth and activation of promatrix metalloproteinase-2 through nuclear factor-kappa B-mediated induction of membrane type 1 matrix metalloproteinase in murine melanoma cells. J Biol Chem 276: 44926-44935, 2001.

18. Leali D, Dell'Era P, Stabile H, Sennino B, Chambers AF, Naldini A, Sozzani S, Nico B, Ribatti D and Presta M: Osteopontin (Eta-1) and fibroblast growth factor-2 cross-talk in angiogenesis. J Immunol 171: 1085-1093, 2003.

19. Furger KA, Menon RK, Tuck AB, Bramwell VH and Chambers AF: The functional and clinical roles of osteopontin in cancer and metastasis. Curr Mol Med 1: 621-632, 2001.

20. Kikuchi H, Saito Y, Sekiya J, Okano Y, Saito M, Nakahata N, Kubohara Y and Oshima Y: Isolation and synthesis of a new aromatic compound, brefelamide, from dictyostelium cellular slime molds and its inhibitory effect on the proliferation of astrocytoma cells. J Org Chem 70: 8854-8858, 2005.

21. Honma S, Saito M, Kikuchi H, Saito Y, Oshima Y, Nakahata N and Yoshida M: A reduction of epidermal growth factor receptor is involved in brefelamide-induced inhibition of phosphorylation of ERK in human astrocytoma cells. Eur J Pharmacol 616: 38-42, 2009.

22. Zhang J, Yamada O, Matsushita Y, Chagan-Yasutan H and Hattori T: Transactivation of human osteopontin promoter by human T-cell leukemia virus type 1-encoded Tax protein. Leuk Res 34: 763-768, 2010.

23. Zhang J, Yamada O, Kida S, Matsushita Y and Hattori T: Down-regulation of osteopontin mediates a novel mechanism underlying the cytostatic activity of TGF- $\beta$. Cell Oncol (Dordr) 39: 119-128, 2016.

24. Zhang J, Yamada O, Sakamoto T, Yoshida H, Iwai T, Matsushita Y, Shimamura $\mathrm{H}$, Araki $\mathrm{H}$ and Shimotohno K: Down-regulation of viral replication by adenoviral-mediated expression of siRNA against cellular cofactors for hepatitis C virus. Virology 320: 135-143, 2004.

25. Ding Z, Wu CJ, Chu GC, Xiao Y, Ho D, Zhang J, Perry SR, Labrot ES, Wu X, Lis R, et al: SMAD4-dependent barrier constrains prostate cancer growth and metastatic progression. Nature 470: 269-273, 2011.

26. Boissy P, Andersen TL, Abdallah BM, Kassem M, Plesner T and Delaissé JM: Resveratrol inhibits myeloma cell growth, prevents osteoclast formation, and promotes osteoblast differentiation. Cancer Res 65: 9943-9952, 2005.

27. Chakraborty G, Jain S, Patil TV and Kundu GC: Down-regulation of osteopontin attenuates breast tumour progression in vivo. J Cell Mol Med 12 (6A): 2305-2318, 2008.

28. Zhao J, Dong L, Lu B, Wu G, Xu D, Chen J, Li K, Tong X, Dai J, Yao S, et al: Down-regulation of osteopontin suppresses growth and metastasis of hepatocellular carcinoma via induction of apoptosis. Gastroenterology 135: 956-968, 2008.

29. Mi Z, Guo H, Russell MB, Liu Y, Sullenger BA and Kuo PC: RNA aptamer blockade of osteopontin inhibits growth and metastasis of MDA-MB231 breast cancer cells. Mol Ther 17: 153-161, 2009.

30. Hijiya N, Setoguchi M, Matsuura K, Higuchi Y, Akizuki S and Yamamoto S: Cloning and characterization of the human osteopontin gene and its promoter. Biochem J 303: 255-262, 1994.

31. Wang D, Yamamoto S, Hijiya N, Benveniste EN and Gladson CL: Transcriptional regulation of the human osteopontin promoter: Functional analysis and DNA-protein interactions. Oncogene 19: 5801-5809, 2000

32. Kim HJ, Lee MH, Park HS, Park MH, Lee SW, Kim SY, Choi JY, Shin HI, Kim HJ and Ryoo HM: Erk pathway and activator protein 1 play crucial roles in FGF2-stimulated premature cranial suture closure. Dev Dyn 227: 335-346, 2003.

33. Joseph EW, Pratilas CA, Poulikakos PI, Tadi M, Wang W, Taylor BS, Halilovic E, Persaud Y, Xing F, Viale A, et al: The RAF inhibitor PLX4032 inhibits ERK signaling and tumor cell proliferation in a V600E BRAF-selective manner. Proc Natl Acad Sci USA 107: 14903-14908, 2010.

34. Demagny H, Araki T and De Robertis EM: The tumor suppressor Smad4/DPC4 is regulated by phosphorylations that integrate FGF, Wnt, and TGF- $\beta$ signaling. Cell Reports 9: 688-700, 2014.

35. Alazzouzi H, Alhopuro P, Salovaara R, Sammalkorpi H, Järvinen H, Mecklin JP, Hemminki A, Schwartz S Jr, Aaltonen LA and Arango D: SMAD4 as a prognostic marker in colorectal cancer. Clin Cancer Res 11: 2606-2611, 2005.

36. Peng B, Fleming JB, Breslin T, Grau AM,Fojioka S, Abbruzzese JL, Evans DB, Ayers D, Wathen K, Wu T, et al: Suppression of tumorigenesis and induction of p15(ink4b) by Smad4/DPC4 in human pancreatic cancer cells. Clin Cancer Res 8: 3628-3638, 2002. 
37. Zhang B, Halder SK, Kashikar ND, Cho YJ, Datta A, Gorden DL and Datta PK: Antimetastatic role of Smad4 signaling in colorectal cancer. Gastroenterology 138: 969-980, 2010.

38. Tian X, Du H, Fu X, Li K, Li A and Zhang Y: Smad4 restoration leads to a suppression of Wnt/beta-catenin signaling activity and migration capacity in human colon carcinoma cells. Biochem Biophys Res Commun 380: 478-483, 2009.

39. Duda DG, Sunamura M, Lefter LP, Furukawa T, Yokoyama T, Yatsuoka T, Abe T, Inoue H, Motoi F, Egawa S, et al: Restoration of SMAD4 by gene therapy reverses the invasive phenotype in pancreatic adenocarcinoma cells. Oncogene 22: 6857-6864, 2003.
40. Tajima K, Ohashi R, Sekido Y, Hida T, Nara T, Hashimoto M, Iwakami S, Minakata K, Yae T, Takahashi F, et al: Osteopontin-mediated enhanced hyaluronan binding induces multidrug resistance in mesothelioma cells. Oncogene 29: 1941-1951, 2010.

41. Pang H, Cai L, Yang Y, Chen X, Sui G and Zhao C: Knockdown of osteopontin chemosensitizes MDA-MB-231 cells to cyclophosphamide by enhancing apoptosis through activating p38 MAPK pathway. Cancer Biother Radiopharm 26: 165-173, 2011. 